\title{
A boa-fé nos contratos comerciais internacionais
}

Tese de Doutorado

Prof. a Associada Maristela Basso

Alexandre Buono Schulz

n. USP 3370315

Faculdade de Direito da Universidade de São Paulo

São Paulo, maio de 2014 
Dedico este trabalho ao João Guilherme, meu filho, razão de tudo, e também a meus queridos pais e à minha amada Maíra. 


\section{RESUMO}

Este trabalho versa sobre a boa-fé na nova lex mercatoria, sob a premissa de sua utilidade como princípio geral para seu ordenamento jurídico. A boa-fé, objetiva e aplicável desde as tratativas até a fase pós-contratual, deve ser entendida como meio de reforço da autonomia da vontade e do pacta sunt servanda, assegurando a consecução da finalidade e do espírito (princípio da materialidade) do contrato, a partir da expectativa legítima ou razoável das partes e do respeito à alocação de riscos ajustadas pelas partes na celebração do contrato. A compreensão da boa-fé deve ser construída a partir da identificação de suas três funções (interpretação, integração e, em caráter excepcionalíssimo) e da criação e implementação dos deveres acessórios.

\section{SUMMARY}

The thesis debates good faith in the new lex mercatoria, based on its utility as a general principle for such legal system. The good faith, objectively understood and applicable during the whole contractual cyclem, from negotiation to post-contractual phase, shall be construed as a means of securing the sanctity of contracts, thus ensuring the achievement of the purpose and spirit (principle of materiality) of the contract, from the perspective of the legitimate or reasonable expectation of the parties and protection of the allocation of risks set forth by the parties when entering into the contract. The understanding of good faith has to be stem from the identification of its three functions (interpretation, integration, and, only in most exceptional cases, correction) and the creation and implementation of accessory duties.

\section{RIASSUNTO}

Questo discute la buona fede nella nuova lex mercatoria, sotto la premessa della sua utilità come principio generale per quello sistema giuridico. La buona fede, oggettivamente intesa e applicabile dale trattative fino alla fase postcontrattuale, deve essere costruita come mezzo per rafforzare l'autonomia della volontà e il pacta sunt servanda, assecurando il raggiungimento della finalità e lo spirito (principio della materialità) del contratto, del punto di vista della aspettativa ragionevole o legitima e 
del rispetto per l'allocazione di rischi definite delle parte alla conclusion del contratto. La comprensione della buona fede deve essere costruita dalla identificazione delle sue tre funzioni (interpretazione, integrazione e, in carattere straordinario, correzione) e dalla creazione e l'attuazione di doveri accessory. 


\section{Introdução}

A proposta deste trabalho partiu do que se concluiu por ocasião da pesquisa de mestrado a respeito da nova lex mercatoria. Nela, apurou-se que a nova lex mercatoria é alvo de críticas, algumas dela com maior interesse prático. Dentre elas, se destacam aquelas que argumentam que a aplicação da nova lex mercatoria é imprevisível, também por ter poucas regras precisas e repousar mais em princípios, tais como o da boa-fé.

A boa-fé, fundamento da nova lex mercatoria, é também objeto dessas críticas, argumentando-se que sua aplicação torna o resultado de uma disputa imprevisível, na medida em que ela não tem conteúdo definido e um sentimento de justiça particular no caso concreto de um árbitro pode ser tratado como aplicação da boa-fé.

Além disso, há críticas quanto à legitimidade da nova lex mercatoria.

A proposta deste trabalho é buscar uma melhor compreensão da boa-fé, a partir das limitações e sentido dados pela ordem pública, a fim de incrementar a previsibilidade e transparência desse princípio na boa-fé.

Para tanto, parte-se da premissa de que sua existência na nova lex mercatoria é desejável, como instrumento de flexibilidade e adaptabilidade necessário para responder à natureza dinâmica do ius mercatorum, direito comercial que é. Não é objeto deste trabalho discutir esta premissa.

$\mathrm{O}$ trabalho, então, é dividido em duas partes, cada uma com dois capítulos. $\mathrm{Na}$ primeira, de construção mais detalhada do contexto acima, fixando o que se entende por lex mercatoria, quais suas fontes, quais são as críticas mencionadas acima, a relação da boa-fé com a ordem pública, analisando brevemente quais as acepções de ordem pública que interessam à nova lex mercatoria. $\mathrm{O}$ segundo capítulo da primeira parte se concentra sobre a boa-fé na legislação comparada, (i) passando por ordenamentos do continente europeu, instrumentos legislativos da União Europeia e instrumentos de soft-law voltados para a Europa; (ii) buscando o entendimento desse princípio na Inglaterra (com destaque para remédios específicos) e nos Estados Unidos, ordenamentos de common law; voltandose em seguida a alguns ordenamentos da (iii) América do Sul; (iv) Ásia; (v) África e (vi) de tradição islâmica, finalizando com a análise da Convenção de Viena das Nações Unidas sobre Contratos de Compra e Venda Internacional de Mercadorias, de 1980, os Princípios UNIDROIT para os Contratos Comerciais Internacionais - fonte de cognição fundamental 
da nova lex mercatoria e recurso imprescindível para este trabalho - e a lista de princípios do Center for Transnational Law - CENTRAL. Concluindo a primeira parte do trabalho, tenta-se um breve apanhado do que se apurou na pesquisa comparada.

A segunda parte do trabalho cuida mais especificamente dos elementos da boa-fé na nova lex mercatoria e também é dividida em duas partes. No terceiro capítulo, o primeiro da segunda parte, aproveitando-se da pesquisa comparada, faz-se as primeiras delimitações da boa-fé, concentrando-se sobre o que ela é e do que ela não é ou não pode ser, a fim de excluir determinadas expectativas e fixar outras quanto a seu conteúdo e funcionamento. Para tanto, buscou-se distinguir a boa-fé de termos relacionados, como por exemplo a equidade. Em seguida, cuidou-se da distinção entre boa-fé objetiva e subjetiva e da relação da boa-fé com (i) os usos como fonte normativa da nova lex mercatoria, com (ii) o pacta sunt servanda e (iii) e com o padrão da razoabilidade, onipresente no comércio internacional. Concluindo o terceiro capítulo, estudou-se a classificação das funções da boa-fé e a extração de deveres acessórios a partir dela.

O último capítulo, mais ainda focado no comércio internacional, primeiro retoma o que se apurou no capítulo anterior para em seguida analisar os elementos da boa-fé. Assim, foram investigados termos específicos usados com a boa-fé que podem contribuir para seu entendimento, mas que com ela não se confunde. Com isso, buscou-se uma proposta preliminar de noção da boa-fé, para poder prosseguir o trabalho. Em seguida, debruçou-se sobre o funcionamento da boa-fé, retomando a ideia de sua objetividade (aliada a uma subjetividade ligada ao caso concreto e não às partes), analisando sua incidência em função da natureza ou categoria de contrato e os desafios e limites da classificação tripartite de suas funções que se propôs (corretiva, de integração e interpretativa), sua aplicação no ciclo contratual, e, por fim, completando o debate em torno do funcionamento da nova lex mercatoria, voltou-se em detalhes para os deveres acessórios.

Por fim, completando o trabalho, elenca-se os elementos centrais para a melhor compreensão da boa-fé, buscando descrever os atributos que podem melhor qualificar seu funcionamento, com o objetivo de aumentar a transparência desse princípio. 


\section{CONCLUSÃO}

A nova lex mercatoria, expressão do direito na sociedade pós-industrial, tem como fontes normativas (i) os usos; (ii) a jurisprudência arbitral e (iii) os princípios gerais de direito, tal como extraídos do artigo 38 do Estatuto da Corte Internacional de Justiça e aqueles específicos do novo ius mercatorum.

Os princípios são o núcleo duro desse direito, ocupam o lugar mais alto na hierarquia das normas da nova lex mercatoria. Dentre eles, pacta sunt servanda e boa-fé são seus os mais fundamentais. São verdadeiros sobreprincípios. Uma vez recepcionada pelo ius mercatorum, a boa-fé, como qualquer outro seu princípio, adquire sentido próprio, destacado daquele que lhe é dado em um mais ordenamentos jurídicos estatais particulares.

Dentre as críticas à nova lex mercatoria, as que têm maior relevo do ponto de vista prático são aquelas que versam sobre seu conteúdo e sua legitimidade. Pela primeira, argumenta-se que seu conteúdo seria vago, incerto e insuficiente e sua aplicação teria resultado previsível. A segunda, que seria fator de desequilíbrio de relações jurídicas em benefício dos mais fortes, desenvolvidos ou ricos e, portanto, não teria legitimidade para dar-lhe suporte.

Ante essas críticas, até em função do papel central que exerce a boa-fé (mencionouse que a grande maioria dos laudos arbitrais a ela faz referência), é crucial melhor compreender esse princípio geral. Primeiro, porque é alvo de muitas críticas pois, para os que sustentam essa crítica, seu conteúdo por demais aberto afeta a previsibilidade e segurança jurídica na medida em que o árbitro poderia denominar de boa-fé o que ele quiser, podendo resultar em decisão arbitrária. Esse cenário é agravado em função da multiplicidade de formas com que se faz referência à boa-fé, tratando-a em conjunto com outras noções que com ela não se confundem. Além disso, entendida como regra de conduta, que pode esmaecer em algumas circunstâncias o pacta sunt servanda, a investigação a seu respeito mostra-se ainda mais importante.

Segundo, em razão da necessidade de desenvolvimento harmonioso da nova lex mercatoria com as demais ordens jurídicas. E o faz por meio da ordem pública, que dá a todos princípios gerais da nova lex mercatoria seu sentido último.

Por isso, cuidou-se de compreender os diferentes níveis ou acepções de ordem pública. Primeiro, aquele de direito puramente interno, que toca a apenas um Estado. Segundo, aquele de direito interno, mas aplicável aos fatos mistos ou multinacionais. É a 
ordem pública vinculada ao direito internacional privado, relevante, por exemplo, para homologação de laudos e sentenças estrangeiras. Além dessas duas acepções e também oriunda de direito inter-estatal, há a ordem pública regional, que representa valores de uma determinada comunidade de Estados, como por exemplo a União Europeia. Há, então, a ordem pública transnacional, que congrega os valores essenciais da nova lex mercatoria, e a ordem pública vinculada ao direito internacional público, superior a todos os demais níveis e acepções. Todo o sentido da ordem pública, em qualquer acepção ou nível, deve ser conforme a a ordem pública vinculada ao direito internacional público.

Interessam à nova lex mercatoria a ordem pública vinculada ao direito internacional público e a ordem pública transnacional.

Feitos esses esclarecimentos, anotou-se que a boa-fé tem relação próxima à ordem pública, sendo também sua expressão e instrumento em determinadas situações.

Nesse contexto, é essencial sublinhar que o contrato, na sociedade pós-industrial, é fonte normativa, interessa não apenas às partes, mas também à coletividade. Ou seja, sua esfera de interesses vai além da soma dos interesses das partes. Essa função dos contratos é ainda mais acentuada considerando que os agentes do comércio internacional têm celebrado cada vez mais contratos associativos e de longo prazo (os ditos contratos relacionais). Pela natureza destes, os efeitos em relação a terceiros tendem a ser mais relevantes e, por outro lado, por perdurarem no tempo, não tem as partes condição de prever toda e qualquer contingiência que pode surgir. Por tal motivo, necessitam de flexibilidade nas regras e seu contrato. É aqui que a boa-fé é chamada a exercer um papel primordial.

Por isso, concebemos a boa-fé como elemento crucial para desenvolvimento da nova lex mercatoria, tanto na esfera bilateral quanto sob a perspectiva do ius mercatorum como um todo. E, há, então, que se ressaltar que este trabalho tem como ponto de partida a conveniência da existência da boa-fé como princípio geral na nova lex mercatoria. Como se observou, muitos comentários a respeito da boa-fé não dizem respeito a seu conteúdo, mas à conveniência de tê-la ou não - discussão que não foi objeto específico deste trabalho.

Assim, para construção da compreensão da boa-fé na nova lex mercatoria, debruçou-se, primeiramente, sobre seu cenário na legislação comparada. Viu-se que a maioria dos ordenamentos jurídicos estatais, incluindo Japão e China, estudados não só preveem a boa-fé, como a entendem em seu sentido objetivo, à exceção da França - em 
que a boa-fé repousa na avaliação da intenção do agente. Entre os ordenamentos nacionais, merecem destaque a Alemanha, a Inglaterra e os Estados Unidos.

É na Alemanha que a boa-fé conheceu e conhece seu mais extenso campo de atução. Apesar dos receios iniciais e de ter sido subvertida na época do nacionalsocialismo, Treu und Glauben é instituição muito sedimentada e consolidada no direito alemão. A partir dela, foi construída uma vasta jurisprudência, formando grupos de casos, criando um sistema próprio e gerando deveres acessórios, às vezes classificados como deveres de proteção, de esclarecimento e de lealdade.

$\mathrm{Na}$ Alemanha, como na maioria dos ordenamentos, a boa-fé é utilizada como critério de interpretação e integração (complementação, criação de deveres acessórios) dos contratos e regula, como em outros países, todo o ciclo contratual, desde suas negociações. Mas é na Alemanha que a boa-fé é também critério de controle dos contratos, podendo corrigi-los em determinadas circunstâncias. Em outros ordenamentos, como na Suíça, essa tarefa cabe ao abuso de direito. Este, aliás, em alguns ordenamentos é tratado em conjunto com a boa-fé, lhe integrando, e em outros como instituto separado. Apesar disso, abuso de direito e boa-fé tem relação próxima, muitas vezes sendo a implementação da proibição ao abuso de direito condicionada pela boa-fé.

Os Estados Unidos, por meio do Uniform Commercial Code e do Restatement (Second) of Contracts, como sistema de common law, passou a prescrever a boa-fé objetiva, como regra de conduta (expressões, como honesty in fact, conjugada com o fair dealing). À semelhança da Inglaterra, a aplicação da boa-fé não é, nos Estados Unidos, reconhecida na fase das tratativas ou negociações, como em outros ordenamentos.

A Inglaterra, por sua vez, representa grande interesse para a compreensão da boafé. Primeiro, porque não há naquele país uma noção geral de boa-fé aplicável a todos os contratos. Um dos argumentos tradicionalmente utilizados para tanto, além de questões envolvendo insegurança para administração da regra, é que o direito das obrigações é inspirado por um espírito adversarial. Por outro lado, o que é também bastante útil para a construção da boa-fé na nova lex mercatoria, na Inglaterra sempre se tutelou e protegeu a expectativa (reliance) legítima ou razoável. Além disso, é na Inglaterra que tem origem a razoabilidade (reasonableness) e o teste do homem razoável. E há também as doutrinas, remédios e deveres específicos (piecemeal solutions) que, em alguma medida, são equivalentes funcionais da boa-fé. Ou seja, essas soluções resolvem problemas reais que, em outros países, é campo de atuação da boa-fé, como noção geral. 
Outra fato interessante é a influência que a implementação de instrumentos comunitários exerce ou pode exercer, no sentido de reconhecimento de uma noção geral de boa-fé. Merece destque também recentes julgados, como o Yam Seng, em que se discute longamente a compatibilidade da boa-fé com o ordenamento. Surpreendentemente, a conclusão que Mr. Leggatt atinge é de que é plenamente compatível com os valores protegidos na Inglaterra, afastando os argumentos tradicionais contra a adoção desse princípio.

No estudo, organizado por ZIMMERMANN e WHITTAKER, envolvendo 30 casos em quase 15 jurisdições europeias, a conclusão foi de que em 2/3 dos casos a harmonia entre as soluções dos ordenamentos foi relevante. E em apenas um desses caso (harmonia da maioria dos ordenamentos), foi a Inglaterra que teve solução diferente.

Após a análise dos ordenamentos nacionais, passou-se à União Européia, aos instrumentos de soft law europeus e transnacionais, incluindo os Princípios UNIDROIT, assim como à CISG.

À exceção da CISG, em que o debate é bastante extenso sobre o reconhecimento da boa-fé como princípio subjacente à Convenção (opinião com a qual nos filiamos) ou não, os demais instrumentos mais relevantes analisados (Princípios de Direito Europeu dos Contratos - PECL, Draft of Common Frame of Reference - DCFR, Proposta de Regulamento do Parlamento Europeu e do Conselho relativa a um direito europeu comum da compra e venda, de 2011) são bastante convergentes. Prevêem a boa-fé, em seu sentido objetivo, como princípio fundamental, baseado na confiança e na consideração do interesse da outra parte.

Concluía a primeira parte do trabalho, passou-se a estudar alguns traços preliminares relativo à boa-fé na nova lex mercatoria, distinguindo a boa-fé de outras noções.

Como se afirmou, a boa-fé é uma noção aberta, cujo conteúdo não pode ser definido em abstrato. A boa-fé só se realiza na medida de sua concretização e especialização. Por isso, sua aplicação, ante a variação dos elementos concretos de cada caso, será diferente conforme o caso. Mesmo assim, ela apresenta uma ratio comum, que servirá como referência para casos futuros.

Ou seja, é correto afirmar que é impossível definir a boa-fé. Mas isso não é um atributo negativo. Trata-se de instrumento de flexibilidade e adaptação da nova le mercatoria, necessário para seu desenvolvimento, considerando seu caráter de work-inprogress. 
Além disso, tratou-se de distinguir discricionariedade e arbitrariedade. O exercício da discricionariedade está vinculada aos requisitos da ordem jurídica que se impõe ao árbitro; é o cumprimento da tarefa legal do árbitro. A arbitrariedade é a patologia.

Em seguida, coube distinguir boa-fé e equidade (entendida como juízos de equidade). Aquela é a própria norma jurídica; pela equidade, o árbitro pode prescindir da aplicação de uma determinada norma, dando preferência a outras. Assim, nas arbitragens et aequo et bono, o árbitro pode, mas não é obrigado a fazer referência aos princípios da nova lex mercatoria. Mas isso não transforma a natureza da boa-fé, alçando-a à equidade. Ao contrário, a referência à equidade em arbitragens de direito, em conjunto com a boa-fé, deve ser evitada por gerar insegurança e imprecisão quanto a seus termos e respectiva compreensão. Além disso, pode ensejar a nulidade do laudo se provado que a norma aplicável foi indevidamente afastada, em preferência a outra escolhida por equidade.

Embora na prática a boa-fé é mencionada (legislações nacionais, doutrina, laudos arbitrais e instrumentos inter- ou transnacionais) por uma variedade de formas - princípio geral, regra, dever, cláusula geral ou standard, ela é princípio geral. Decorre dessa natureza a extração de normas inferiores, mas sujeitas à boa-fé que dela adquirem sentido. Não obstante essa fluidez terminológica na prática, é o que importa fixar.

Ainda no Capítulo 3, houve a oportunidade de refletir sobre a relação da boa-fé, como princípio geral da nova lex mercatoria, com as fontes da nova lex mercatoria (jurisprudência arbitral, usos e princípios gerais)

O mais relevante é a interação entre boa-fé e pacta sunt servanda. São pares, não se sujeitando um ao outro. Devem se acomodar. Como se afirmou, entendida como veículo de proteção da confiança e da expectativa legítima ou razoável, a boa-fé não contraria o princípio pacta sunt servanda (exceto nas hipóteses de ofensa a ordem pública, em que a dinâmica é outra), mas apenas o reforça e aumenta a segurança contratual na medida em que, tutelando o conteúdo real, material (não formal) das obrigações (o espírito do contrato, princípio da materialidade), em uma abordagem teleológica do contrato (sua finalidade), assegura a alocação de riscos feita pelas partes.

Essa partilha de riscos é o ponto crucial de avaliação da boa-fé. Não pode o árbitro alterar a esfera de riscos ajustada pelas partes.

Mais adiante, debruçou-se sobre a relação entre boa-fé e proibição ao abuso de direito, concluindo-se que ele integra a boa-fé e dela adquire sentido na sua concretização. Seus limites e modo de operação são informados pela boa-fé. É meio de concretização da boa-fé. 
Continuando na investigação da boa-fé e sua interação com as fontes retomou-se a ideia de que os árbitros que concretizam a boa-fé, extraindo-lhe e enunciando regras, deveres (acessórios, secundários, anexos ou instrumentais) e princípios a ela subordinados.

Boa-fé e usos, por sua vez, têm efeitos recíprocos. Trata-se de relação de causa e efeito e dependência. A boa-fé, por meio da opinio iuris, condiciona a formação do uso como fonte normativa, mas, por outro lado, os usos dão a medida de conformidade de um comportamento na concretização da boa-fé. Essa dinâmica entre usos e boa-fé também reforça a segurança contratual, ao proteger a expectativa razoável das partes, informada por critérios objetivos.

Em seguida, buscou-se estudar os termos que são utilizados às vezes com sinônimos, às vezes em conjunto e outras vezes para esclarecimento do que se deve entender por boa-fé.

Das noções analisadas (lealdade, sinceridade, franqueza, transparência, fidelidade, expectativa, honestidade, confiança, credibilidade, cooperação, prudência, diligência, razoabilidade, equidade ou mesmo justiça), alguns (honestidade, p. exemplo) devem ser evitados, eis que não apenas não contribuem para o entendimento e construção da boa-fé, como também podem gerar incertezas ao aportar sentido que lhe é estranho (como um caráter subjetivo da boa-fé).

Dentre eles, confiança, transparência, lealdade, cooperação, diligência e razoabilidade, apesar de não aportarem elementos mais concretos, sendo também noções abertas, contribuem para o entendimento da boa-fé.

A confiança (ou expectativa) razoável ou legítima representa um importante parâmetro para avaliação e operacionalização da boa-fé. O termo transparência também é útil, principalmente na implementação da proibição do venire contra factum proprium e do abuso de direito.

A lealdade (negocial) é o fair dealing e atribui o caráter objetivo à boa-fé e tem também o sentido, como a cooperação, de preservar o interesse comercial da outra parte na medida necessária para consecução da finalidade do contrato. Diligência (e prudência) assim como razoabilidade (teste do razoável, p. ex.) são critérios de avaliação de um comportamento ou uma circunstância segundo a boa-fé.

Chegando à última parte da tese, que cuida da operação da boa-fé, importou retomar a ideia de que a boa-fé na nova lex mercatoria é objetiva, mas também ao mesmo tempo subjetiva. Não em relação ao contratante e sua intenção. O polo objetivo aporta os elementos não relacionados ao caso, constantes e invariáveis para além da relação em 
concreto analisada (usos, standards, deveres reconhecidos no comércio internacional, entre outro); o polo subjetivo, por sua vez, representa a variabilidade do conteúdo da boa-fé em função das circunstâncias ou elementos de fato do caso concreto (as partes, sua qualidade, o contrato, seu tipo, duração e finalidade, obrigações do caso específico e os eventos ocorridos após sua celebração).

Em seguida, reforçando-se a incid6encia da boa-fé a todas as categorias de contrato, concluiu-se que nos contratos associativos ou de longo, em função das circunstâncias de fato, deve haver mais oportunidades para que a boa-fé seja chamada a intervir, se comparado a um contrato de execução instantânea. Mas verificada uma situação na prática exigindo aplicação da boa-fé, ela é igualmente aplicável e mambas as categorias.

Em relação às funções da boa-fé, propôs-se a seguinte classificação: (i) corretiva; (ii) integrativa e (iii) interpretativa. Isso não obstante a dificuldade de distinção entre interpretação e integração, na medida em que, no comércio internacional, a determinação do conteúdo da obrigação e do contrato é obra interpretativa. Mesmo assim, a distinção parece interessante e útil a fim de orientar a complementação cautelosa do contrato, quando necessária e na medida não necessária para não afetar a alocação de risco entre as partes. Nesse sentido, postulou-se, a partir do teste existente no direito inglês para implicação de um termo (implication of a term), com as adaptações que se entendeu cabíveis, os seguintes requisitos cumulativos: são que a obrigação ou dever a ser criado ou imposto seja: (i) razoável; (ii) necessário(a) para assegurar o cumprimento da finalidade do contrato; (iii) precisa ser óbvio(a) a tal ponto que "não é preciso dizer" (it goes without saying), pelo menos no comércio ou setor específico; (iv) deve ser passível de clara expressão e (v) não pode contradizer um termo expresso do contrato, exceto nos casos de violação da ordem pública transnacional ou da ordem pública vinculada ao direito internacional público ${ }^{1}$.

A função corretiva deve entrar em cena na nova lex mercatoria a não ser casos excpecionais, de grave abalo da economia do contrato ou de ordem pública. É a correta aplicação (excepcional e preservando sempre que possível a alocação de risco das partes) que pode contribuir para afastar o receio de imprevisibilidade que ronda a boa-fé - apesar de, como visto, na prática arbitral ela não se justificar.

\footnotetext{
${ }^{1}$ Vide http://www.bailii.org/uk/cases/UKPC/2009/10.html: "the question of implication arises when the instrument does not expressly provide for what is to happen when some event occurs"; "the central idea that the proposed implied term must spell out what the contract actually mean".
} 
Nesse sentido, a fim de permitir uma maior compreensão da boa-fé, contribuindo para a transparência e maior previsibilidade de sua concretização, reomendou-se: (i) que se evite a utilização de termos e noções que não apenas não aportam qualquer sentido à boafé, como podem efetivamente prejudicar sua compreensão (como por exemplo e especialmente a equidade); e (ii) a identificação pelos árbitros na medida possível, qual é a função utilizada para a aplicação da boa-fé no caso concreto, qual seu alcance e limites.

Mostrou-se que a boa-fé se aplica a todo o ciclo contratual, desde as tratativas, até sua extinção e também o período que pós-contratual e identificou-se os deveres acessórios informados ou originados da boa-fé por obra da jurisprudência arbitral e das fontes materiais da nova lex mercatoria, tais como o o estoppel ou venire contra factum proprium, dever de informação, de minimização de danos, entre outros. Há, entre eles, deveres que se consolidam de tal forma e acabam por se destacar da boa-fé. Passam a ser tratados de forma autônoma e, às vezes, alçados até de princípios. É uma relação distinta do que a boa-fé tem com o pacta sunt servanda, de acomodação.

E esse movimento de consolidação e de se destacar é muito relevante para o desenvolvimento da nova lex mercatoria, seja porque por um lado ajudam a construir o próprio conteúdo da boa-fé e por outro tornam o ius mercatorum mais previsível.

O cenário ideal é, na nova lex mercatoria, a conjugação de uma noção geral de boafé, a fim de permitir e garantir a flexibilidade e adaptabilidade desse direito. A combinação da regulação de civil law com a common law - que, dentre os ordenamentos estudados, parece estar mais próxima do regime da boa-fé nos Estados Unidos (como framework e não como conteúdo e funcionamento).

Ao final, identificou-se como elementos centrais da boa-fé: (i) ela implica um dever positivo, de agir, para assegurá-la; (ii) sua operação e compreensão deve ser feita de forma a buscar a consecução da finalidade do contrato e (iii) ela deve necessariamente tomar como ponto de partida e referência, a alocação de riscos acordada pelas partes, salvo nos casos de violação de ordem pública.

A partir desses elementos, propôs-se a seguinte qualificação da boa-fé e seu funcionamento na nova lex mercatoria: (i) princípio geral ou sobreprincípio; (ii) objetivo, como conduta externa às partes, mas comportando uma subjetividade representada pela variabilidade das circunstâncias de fato; (iii) a partir do qual são extraídos regras, deveres e outros princípios (cujo sentido é informado pela boa-fé); (iv) voltado para aumentar a segurança das relações contratuais e também aportar flexibilidade a elas e ao direito; (vi) tendo como referência principal a alocação de riscos feita pelas partes; (vi) baseado na 
tutela da confiança ou da expectativa legítima ou razoável; (vii) que exige das partes uma conduta positiva (de agir para assegurar a boa-fé), representada por (a) um comportamento ou conduta leal; (b) transparente; (c) diligente; (d) razoável, devendo sempre considerar os interesses contratuais da outra parte, (f) com ela devendo cooperar na medida necessária para cumprimento de suas obrigações e do contrato (e essa é a medida da consideração dos interesses do outro), (viii) de modo a assegurar a consecução de finalidade do contrato e a materialização de seu espírito. 


\section{BIBLIOGRAFIA}

AJANI, Gianmaria, SERAFINO, Andrea, TIMOTEO, Marina, Diritto dell'Asia orientale Trattato di diritto comparato diretto da Rodolfo Sacco, Torino, Utet, 2007.

AMOUSSOU-GUÉNOU, Roland, Perspectives des Principes Asean (Ou Asiatiques) du droit des contrats, in Revue de droit des affaires internationales, 2005, pp. 573-591.

ANCEL, Bertrand, The Tronc Commun Doctrine - Logics and Experience in International Arbitration, in Journal of International Arbitration, 1990, pp. 65-72.

ARAÚJO, Nádia de, A Nova Lei de Arbitragem e os "Princípios Uniformes dos Contratos Comerciais Internacionais", elaborados pelo UNIDROIT, in CASELLA, Paulo Borba (coord.), Arbitragem - Lei Brasileira e Praxe Internacional, 2ª ed., São Paulo, LTr, 1999, pp. 133-62.

ARISTÓTELES, Ética a Nicômaco, trad. port. BINI, Edson, São Paulo, Edipro, 2002.

ARNALDEZ, Jean-Jacques, Note to ICC Award No. 6653, in Clunet, 1993, pp. 1047-1053 (http://www.trans-lex.org/196665).

ARNAUD, André Jean, Entre modernité et mondialisation - Leçons d'histoire de la philosophie du droit et de l'Etat, 2a ed., Paris, LGDJ, 2004.

ATIYAH, Patrick Selim, The rise and fall of freedom of contract, New York, Oxford, 1985.

AUER, Marietta, The Structure of Good Faith - A Comparative Study of Good Faith Arguments, 2006 cf. disponível [online] in http://ssrn.com/abstract=945594.

AZEVEDO, Luiz Carlos de, Introdução Histórica do Direito, São Paulo, Revista dos Tribunais, 2005.

BAPTISTA, Luiz Olavo, A Boa Fé nos contratos internacionais, in Revista de Direito Bancário, do Mercado de Capitais e da Arbitragem, v. 6, n. 20, 2003, pp. 24-46. , Arbitragem Comercial e Internacional, São Paulo, Lex, 2011. , Contratos Internacionais, São Paulo, Lex, 2010. , Parallel Arbitrations - waivers and estoppel, in CREMADES,

Bernardo M., LEW, Julian D. M. (org.), Parallel State and Arbitral Procedures in International Arbitration, ICC Publication, Paris, 2005, pp. 127-151. , O Projeto de princípios para Contratos Comerciais internacionais da UNIDROIT - Aspectos de direito internacional privado, in BONELL, Michael Joachim e CHIPANI, Sandro (org.), Il Progetto UNIDROIT "Principi per i contratti commeciali 
internazionali" e l'unità e speificità del sistema giuridico latinoamericano, Padova, Cedam, 1996, pp. 23-33.

BAR, Christian von, CLIVE, Eric, SCHULTE-NÖLKE, Hans, Principles, Definitions and Model Rules of European Private Law - Draft Common Frame of Reference (DCFR) Prepared by the Study Group on a European Civil Code and the Research Group on EC Private Law (Acquis Group), Munique, Sellier, 2009, cf. disponível [online] in http://ec.europa.eu/justice/contract/files/european-private-law_en.pdf.

BART, Jean, La lex mercatoria au moyen age - mythe ou realitè?, in LEBEN, Charles; LOQUIN, Eric; SALEM, Mahmoud (org.), Souveraineté étatique et marchés internationaux à la fin du 20ème siècle, à propos de 30 ans de recherche du CREDIMImélanges en l'honneur de Philippe Kahn, Paris, Litec, 2000, pp. 10-22.

BASEDOW, Jürgen, International Uniform Law Conventions and the UNIDROIT Principles of International Commercial Contracts, in Uniform Law Review, 2000, pp. 12939.

BASSO, Maristela, A Autonomia da Vontade nos Contratos Internacionais de Comércio, in Direito e Comércio Internacional - Tendências e Perspectivas - Estudos em Homenagem ao Professor Irineu Strenger, São Paulo, LTr, pp. 42-62.

Âmbito de Aplicação dos Princípios UNIDROIT sobre os Contratos Comerciais Internacionais, in Revista Jurídica UNIGRAN, 1999, pp. 48-57. , Contratos Comerciais do Comércio - Negociação, Conclusão,

Prática, $2^{a}$ ed., Porto Alegre, Livraria do Advogado, 1998. , Curso de Direito Internacional Privado, São Paulo, Atlas, 2009.

BAXTER, R. R., International Law in "Her Infinite Variety", in International and Comparative Law Quarterly, v. 29, 1980, pp. 549-566.

BEALE, H., General Clauses and Specific Rules in the Principles of European Contract Law - The Good Faith Clause, in GRUNDMANN, S., MAZEAUD, D., General Clauses and Standards in European Contract Law, the Netherlands, Kulwer, 2006, pp. 205-18.

BEATSON, Jack, FRIEDMANN, Daniel (ed.), Good Faith and Fault in Contract Law, New York, Oxford, 1995.

BERGER, Klaus Peter, The concept of the "Creeping Codification" of Transnational Commercial Law, cf. disponível [online] in www.Trans-Lex.org/000004 [15.12.2009]. , The creeping codification of the lex mercatoria, The Hague, Boston, Kluwer Law International, 1999. 
The relationship between the UNIDROIT Principles of International Commercial Contracts and the new lex mercatoria, in Uniform Law Review, 2000, pp. 153-70.

BERGER, Peter L., LUCKMANN, Thomas, Modernität, Pluralismus und Sinnkrise - Die Orientierung des modernen Menschen, trad. port. de Edgar Orth, Modernidade, Pluralismo e Crise de Sentido - A Orientação do Homem Moderno, Petrópolis, Vozes, 2004.

BERGER, Michel, Préjudice indemnisable et droit international des contrats, in Revue de droit des affaires internationals, v. 4, 2004, pp. 427-443.

BERNARDINI, Piero, Is the duty to cooperate in long-term contracts a substantive transnational rule, in GAILLARD, Emmanuel (ed.), Transnational Rules in International Commercial Arbitration, ICC Publishing, n. 480, Paris, 1993, pp. 137-145, cf. disponível [online] in www.Trans-Lex.org/l10000.

BERMAN, Paul Schiff, From international law to law and globalization, in Columbia Journal of Transnational law, v. 43, n. 2, 2005, pp. 485-556.

BERMAN, Harold J.; KAUFMAN, Colin, The Law of International Commercial Transactions (Lex Mercatoria), in Harvard International Law Journal, Cambridge, 1978, pp. 221-77.

, Private commercial law in the cotton industry - creating cooperation through rules, norms and institutions, in Michigan law Review, 2001, pp. 1724-90.

BOBBIO, Norberto, Contributi ad un dizionario giuridico, Torino, G. Giappichelli, 1994, pp. 257-79.

Da Estrutura à função - novos estudos de teoria do direito, São Paulo, Manole/Bovespa, 2006.

, Il positivismo giuridico, trad. port. de Márcio Pugliesi, Edson Bini,

Carlos E. Rodrigues, O Positivismo Jurídico - Lições de Filosofia do Direito, São Paulo, Ícone, 2006.

Teoria dell'ordinamento giuridico, trad. port. de Maria Celeste Cordeiro Leite dos Santos, 10ª ed., Brasília, Universidade de Brasília, 1999.

BOBBIO, Norberto; MATEUCCI, Nicola; PASQUINO, Gianfranco, Dizionario di Politica, trad. port. de Carmen C. Varriale et al., Dicionário de Política, 12a ed., v. 1 e v. 2, Brasília, Universidade de Brasília, 2004.

BODIN, Didier, Le pluralisme juridique en droit international privé, in Archives de philosophie du droit, n. 49, 2006, pp. 275-316. 
BOGART, D., Good Faith and Fair Dealing in Commercial Leasing - The Right Doctrine in the Wrong Transactionsi, in Marshall Law Review, 2007-8, pp. 275-324.

BONELL, Michael Joachim, Do we need a Global Commercial Code, in Uniform Law Review, 2000, pp. 469-82.

, The UNIDROIT Principles and Transnational Law, in Uniform Law Review, 2000, pp. 199-218.

, The UNIDROIT Principles of International Commercial Contracts The first 50 or so decisions, in New Trends in International Trade Law - Contributions on the Occasion of the 10th Anniversary of the International Trade Law Course, Torino, G. Giappichelli, 2000, pp. 65-80.

, The UNIDROIT Principles of International Commercial Contracts and CISG - Alternatives or Complementary Instruments, in Uniform Law Review, 1996, pp. 26-39.

Un "codice" internazionale del diritto dei contratti - I Principi

UNIDROIT dei contratti commerciali internazionali, $2^{\mathrm{a}}$ ed. Milano, Giuffrè, 2006. , Unidroit Principles 2004 - The New Edition of International

Commercial Contracts adopted by the International Institute for the Unification of Private Law, in Uniform Law Review, 2004, pp. 5-40.

BORTOLOTTI, Fabio, Manuale di diritto commerciale internazionale, v. 1, $2^{\mathrm{a}}$ ed., Padova, Cedam, 2003.

The ICC Model Contracts, in New Trends in International Trade Law - Contributions on the Occasion of the $10^{\text {th }}$ Anniversary of the International Trade Law Course, Torino, G. Giappicheli, 2000, pp. 81-97.

The UNIDROIT Principles and the arbitral tribunals, in Uniform Law Review, 2000, pp. 141-52.

BOSCHIERO, Nerina, La lex mercatoria nell'era della globalizzazione - considerazioni di diritto internazionale pubblico e privato, in Sociologia del Diritto, v. 32, n. 2-3, 2005, pp. 83-155.

BOWDEN, P., L'interdiction des se contredire au détriment d'autrui (estoppel) as a Substantive Transnational Rule in International Commercial Arbitration, in GAILLARD, Emmanuel (ed.), Transnational Rules in International Commercial Arbitration, Paris, ICC Publishing, n. 480, 1993, pp. 125-136, cf. disponível [online] in www.TransLex.org/110600.

BROWNLIE, Ian, Principles of Public International Law, $5^{\text {a }}$ ed, New York, Oxford, 1998. 
BROWNSWORD, R., Positive, Negative, Neutral - the Reception of Good Faith in English Contract Law, in BROWNSWORD, R., HIRD, e HOWELLS, G. (ed), Good Faith in Contract - Concept and Context, Aldershot, Dartmouth, 1999, pp. 13-40.

BUCHER, Andreas, La Dimension Sociale du Droit International Privé, Leiden/Boston, Martinus Nijhoff, 2010.

BURTON, Steven J., Judging in good faith, Cambridge, Cambridge, 1992.

CALliGAN, Dennis J., Law in Modern Society, New York, Oxford University Press, 2007.

CASELLA, Paulo Borba, Utilização no Brasil dos Princípios UNIDROIT Relativos aos Contratos Comerciais Internacionais, in CASELLA, Paulo Borba (coord.), Arbitragem Lei Brasileira e Praxe Internacional, 2a ed., São Paulo, LTr, 1999, pp. 99-105.

CASTELLS, Manuel, The rise of the network society, trad. port. de Roneide Venâncio Majer, A sociedade em rede - A era da informação - economia, sociedade e cultura, v. 1, São Paulo, Paz e Terra, 1999.

CASTILLA, Gustavo Ordoqui, Buena Fe en los Contractos, Madri, Reus, 2011.

CASUCCI, Felice, Il diritto 'plurale' - Pluralismo delle fonti e libera circulazione delle norme giuridiche, Napoli, Edizioni Scientifiche Italiane, 2004.

COQUILLETTE, Daniel R., Incipit Lex Mercatoria, Que, Quando, Ubi, Inter Quos et de Qubius Sit - El Tratado de Lex Mercatoria en el Little Red Book de Brístol, in PETIT, Carlos (org.), Del Ius Mercatorum al Derecho Mercantil -3 Seminario de Historia del Derecho Privado, Sitges 28-30 de Mayo de 1992, Madrid, Marcial Pons, 1997.

CORDEIRO, António Menezes, Da Boa-Fé no Direito Civil, Coimbra, Almedina, 2001.

CANARIS, Claus-Wilhelm, Grigoleit, Hans Christoph, Interpretation of Contracts, in HARTKAMP, Arthur, HESSELINK, Martijn W., HONDIUS, Ewoud H. et. al., Towards a European Civil Code, $4^{\mathrm{a}}$ ed., Kluwer, the Netherlands, 2004, pp. 445-69, cf. disponível [online] in http://www.trans-lex.org/103950.

CARTWRIGHT, John, Protecting legitimate expectations and estoppel - English Law, in FAUVARQUE-COSSON, Bénédicte (ed.), La Confiance Légitime et l'Estoppel, Paris, Société de Législation Comparée, 2007, pp. 321-48.

CARVAJAL-ARENAS, Lorena, Good faith in the lex mercatoria - an analysis of arbitral practice and major western legal systems, Tese (Univeristy of Portsmouth), 2011, cf. disponível [online] in http://eprints.port.ac.uk.

COHN, Haim H., The Grotian Concept of Good faith, in Tel Aviv University Studies in Law, 1985-86, pp. 9-19. 
COUTO E SILVA, Clóvis, A obrigação como processo, Rio de Janeiro, FGV, 2006.

CREMADES, Bernardo M., Good Faith in International Arbitration, in American University International Law Review, v. 27, n. 4, 2013, pp. 761-90.

CUTLER, A. Claire, Private Power and Global Authority - Transnational Merchant Law in the Global Political Economy, Cambridge, Cambridge, 2003.

DAL RI JÚNIOR, Arno, História do Direito Internacional - Comércio e Moeda - Cidadania e Nacionalidade, Florianópolis, Fundação Boiteux, 2004.

DALHUISEN, Jan H., Dalhuisen on Transnational and Comparartive Commercial, Financial and Trade Law, $3^{\mathrm{a}}$ ed., Portland, Hart, 2007.

Custom and Its Revival in Transnational Private Law, in Duke Journal of Comparative International Law, v. 18, 2007-2008, pp. 338-70.

DANIS-FATÔME, Anne, Apparence et Contrat, Paris, LGDJ, 2004.

DASSER, Felix, Lex Mercatoria - Critical Comments on a Tricky Topic, 2003, cf. disponível [online] in http://www.homburger.ch/fileadmin/publications/LMCRIT.pdf [4.1.2009].

DAVID, René, Il diritto del commercio internazionale - un nuovo compito per i legislatori nazionali o una nuova lex mercatoria?, inRivista di Diritto Civile, 1976, I, pp. 577-90.

, Les Grands Systèmes du Droit Contemporains, trad. port. de

Hermínio A. Carvalho, Os Grandes Sistemas do Direito Contemporâneo, $4^{\mathrm{a}}$ ed., São Paulo, Martins Fontes, 2002.

DE LY, Filip, Les Clauses D'Interpretation Dans Les Contrats Internationaux (Qualification, Definition, Accord Complet, Intitules, Langue, Modification, Renonciation Et Nullite Partielle), in Revue de droit des affaires internationales, n. 6, 2000, pp. 719-812. , Les clauses mettant fin aux contrats internationaux, in Revue de droit des affaires internationales, n. 7, 1997, pp. 801-836.

DE MASI, Domenico (org.), L'avvento post-industriale, trad. port. de Ana Maria Capovilla, Luiz Sérgio do Nascimento Henrique et al., A sociedade pós-industrial, $3^{\mathrm{a}}$ ed., São Paulo, Senac, 2000.

DEL VECCHIO, Giorgio, Storia della filosofia del diritto, trad. esp. de Luis Legaz y Lacambra, Historia de la filosofía del derecho, $2^{\mathrm{a}}$ ed., Barcelona, Bosch, 1964.

DELLA VALLE, Martim, Da decisão por eqüidade na arbitragem comercial internacional, Tese (USP), 2009.

DELMAS-MARTY, Mireille, Les forces imaginantes du droit - le relatif e l'universel, Paris, Seuil, 2004. 
DERAINS, Y., L'Obligation de Minimiser le Dommage dans la Jurisprudence Arbitrale, in Revue de droit des affaires internationales, $\mathrm{n}$. , 1987, cf. disponível [online] in www.trans-lex.org/120100, pp. 375-82.

DEZALAY, Yves; GARTH, Bryant, Merchants of Law as Moral Entrepreneurs Constructing International Justice from the Competition for Transnational Business Disputes, in Law \& Society Review, v. 29, n. 1, 1995, pp. 27-64.

DEZALAY, Yves; TRUBEK, David M., A reestruturação global $e$ o direito $-a$ internacionalização dos campos jurídicos", in FARIA, José Eduardo Campos de (org.), Direito e globalização econômica, São Paulo, Malheiros, 1998, pp. 29-80.

DIESSE, François, The requirement of contractual cooperation in international trade, in Revue de droit des affaires internationales, n. 7, 1999, pp. 737-782.

DOLINGER, Jacob, A Ordem Pública Internacional em seus Diversos Patamares, in RT, v. 828,2004 , p. 38

Direito Internacional Privado - Parte Geral, Rio de Janeiro,

Renovar, $8^{\mathrm{a}}$ ed., 2005.

DORFMAN, Rosalee S., The Regulation of Fairness and Duty of Good Faith in English Contract Law - A Relational Contract Theory Assessment, in Leeds Journal of Law \& Criminology, v. 1, n. 1, 2013 cf. disponível [online] in http://criminology.leeds.ac.uk/files/2013/09/Fairness-English-Contract-Law_Dorfman.pdf, pp. 91-116.

DRAETTA, Ugo, Les clauses de force majeure et de hardship dans les contrats internationaux, in Revue de droit des affaires internationales, n. 3-4, 2002, pp. 347-56. , The notion of consequential damages in international trade practice

- a merger of common law and civil law concepts, in Revue de droit des affaires internationales, n. 4, 1991, pp. 487-98.

DRAETTA, U., LAKE, Ralph B., Les clauses pénales et les pénalités dans la pratique du commerce international, in Revue de droit des affaires internationales, n. 3, 1993, pp. 26172.

DUKE, Arlen, Universal Duty of Good Faith - An Economic Perspective, Monash University Law Review, 2007, pp. 182-.202

DUONG, Lêmy, Le raisonnable das les principes du droit européen des contrat, in Revue internationale de droit comparé, v. 60, n. 3, pp. 701-27.

FARALLI, Carla, Certezza del diritto o diritto alla certezza?, in Materiali per una Storia della Cultura Giuridica, v. 27, n. 1,1997, pp. 89-104. 
La filosofia del diritto contemporanea, trad. port. de Candice Premaor Gullo, A filosofia contemporânea do direito - Temas e desafios, Martins Fontes, São Paulo, 2006.

, Vicende del pluralismo giuridico - tra teoria del diritto, antropologia e sociologia, in Sociologia del Diritto, v. 26, n. 3, 1999, pp. 89-102.

FARNSWORTH, E. ALLAN, Duties of good faith under the UNIDROIT Principles, relevant international conventions and national laws, in Tulane Journal of International and Comparative Law, v. 3, 1995, pp. 47-63.

FAUVARQUE-COSSON, Bénédicte, La confiance legitime et l'Estoppel - Rapport général, in FAUVARQUE-COSSON, Bénédicte (ed.), La Confiance Légitime et l'Estoppel, Paris, Société de Législation Comparée, 2007, pp. 9-62.

FERRARESE, Maria Rosaria, Diritto sconfinato - inventiva giuridica e spazi nel mondo globale, Roma-Bari, Laterza, 2006.

, Maria Rosaria, Il diritto al presente - globalizzazione e tempo delle istituzioni, Bologna, Il Mulino, 2002.

, La lex mercatoria tra storia e attualità - da diritto dei mercanti a lex per tutti?, in Sociologia del Diritto, v. 32, n. 2-3, 2005, pp. 157-78.

, Le istituzioni della globalizzazione - diritto e diritti nella società transnazionale, Bologna, Il Mulino, 2000.

FERRARI, Franco, General Principles and International Commercial Law Conventions A Study of the 1980 Vienna Sales Convention and the 1988 Unidroit Conventions, in Uniform Law Review, 1997, pp. 465-73.

FERRARI, Vincenzo, Quesiti sociologici sulla lex mercatoria, in Sociologia del Diritto, v. 32, n. 2-3, 2005, pp. 7-27.

FLECHTNER, H., Comparing the general good faith provisions of the PECL and the UCC - appearance and reality, in Pace International Law Review, 2001, v. 13, pp. 295-338.

FONTAINE, M., L'avant-projet d'Acte uniforme OHADA sur le droit des contrats - vue d'ensemble, in Revue de Droit Uniforme, 2008, n. 1-2, cf. disponível [online] in http://www.unidroit.org/english/publications/review/articles/2008-1\&2/203-215.pdf, pp. 203-215.

FORTHIER, Vincent, Le raisonnable dans le contrat du commerce international, in Journal du Droit International, v. 123, n. 2, 1996, pp. 315-79. 
FORTIER, L. Yves, New trends in governing law - the new, new lex mercatoria, or, back to the future, in ICSID Review - Foreign Investment Law Journal, v. 16, n. 1, 2001, pp. 109.

FORTUNATI, Maura, La lex mercatoria nella tradizione e nella recente ricostruzione storico-giuridica, in Sociologia del Diritto, v. 32, n. 2-3, 2005, pp. 29-41.

FRIGNANI, Aldo, L'arbitrato commerciale internazionale - v. XXXIII - Trattato di diritto commerciale e di diritto pubblico dell'economia diretto da Francesco Galgano, Padova, Cedam, 2004.

FRY, James D., Désordre Public International Under the New York Convention - Wither Truly International Public Policy, in Chinese Journal of International Law, v. 8, n. 1, 2009, pp. 81-134, cf. disponível [online] in http://chinesejil.oxfordjournals.org/content/8/1/81.full.pdf+html.

GAILLARD, Emmanuel, La distinction des principes généraux du droit et des usages du commerce international, in Études offertes à Pierre Bellet, Paris, Litec, 1991, pp. 203-17.

, L'interdiction de se contredire au detriment d'autrui comme principe general du droit du commerce international, in Revue de l'Arbitrage, 1985, cf. disponível [online] in as www.trans-lex.org/123000, pp. 241-59.

Legal Theory of International Arbitration, Leiden- Boston, Martinus

Nijhoff, 2010.

Transnational Law - A Legal System or a Method of Decision Making?, in Arbitration International, v. 17, n. 1, 2001, pp. 59-71.

, Trente ans de lex mercatoria - pour une application selective de la methode des principes generaux du droit, in Journal du Droit International, v. 122, n. 1, 1995, pp. 5-30.

GAILLARD, Emmanuel, SAVAGE, John (ed.), Fouchard Gaillard Goldman on International Commercial Arbitration, The Hague, Kluwer Law International, 1999.

GALGANO, Francesco, L'equità degli arbitri, in Rivista Trimestrale di Diritto $e$ Procedura Civile, n. 2, 1991, pp. 409-16.

, La globalizzazione nello specchio del diritto, Bologna, Il Mulino, 2005.

, Lex Mercatoria, Bologna, Il Mulino, 2001.

GALGANO, Francesco; MARRELLA, Fabrizio, Diritto del commercio internazionale, Padova, Cedam, 2005. 
GALLO, P., Unjust Enrichment - A Comparative Analysis, in American Journal of Comparative Law, v. 40, 1992, pp. 431-66.

GAMBARO, Antonio, Alcuni appunti sugli aspetti istituzionali della cosidetta globalizzazione, in Sociologia del Diritto, v. 32, n. 2-3, 2005, pp. 241-7.

GAMBARO, Antonio, SACCO, R., Sistemi Giuridici Comparati - Trattato di Diritto Comparato diretto da Roldofo Sacco, $3^{\mathrm{a}}$ ed.,Torino, Utet, 2009.

GARRO, A. M., Reconciliation of Legal Traditions in the U.N. Convention on Contracts for the International Sale of Goods, in 23 International Lawyer (1989), cf. disponível [online] in http://www.cisg.law.pace.edu/cisg/biblio/garrol.html, pp. 443-483. The Gap-Filling Role of the Unidroit Principles in International Sales Law - Some Comments on the Interplay between the Principles and the CISG, in Tulane Law Review, n. 69, 1994-1995, pp. 1149-90.

GHESTIN, Jacques, L'analyse Économique de la Clause Générale, in GRUNDMANN, S., MAZEAUD, D., General Clauses and Standards in European Contract Law, the Netherlands, Kulwer, 2006, pp. 165-87.

GIARDINA, Andrea, La lex mercatoria e la certezza del diritto nei commerci e negli investimenti internazionali, in Rivista di Diritto Internazionale Privato e Processuale, v. 28, n. 3, 1972, pp. 461-70.

GILISSEN, John, Introduction historique au droit, trad. port. de António Manuel Botelho Hespanha e Manuel Luís Macaísta Malheiros, Introdução Histórica ao Direito, $4^{\mathrm{a}}$ ed., Lisboa, Calouste Gulbenkian, 2003.

Introduction à l'étude comparée du pluralisme juridique, in GILISSEN, John (org.), Le pluralisme juridique, Bruxelles, Université de Bruxelles, 1971. GOLDMAN, Berthold, Frontières du droit et lex mercatoria, in Archives de philosophie du droit, n. 9, 1964, pp. 177-92.

, Nouvelles Réflexions sur la Lex Mercatoria, in Festschrift Pierre Lalive, Basel, Frankfurt a.M., 1993, pp. 241-55.

La lex mercatoria dans les contrats et l'arbitrage internationaux réalité et perspectives, in Journal du Droit International, 1979, pp. 475-99.

, The applicable law - general principles of law - the "lex mercatoria", in Contemporary problems in international arbitration, Julian D.M. Lew, Center for commercial Studies, London, 1986, pp. 113-25. 
GOLDSCHMIDT, Levin, Universal-geschichte des Handelsrecht, trad. it. de Vittorio Pouchain, Storia universale del diritto commerciale, Torino, Unione tipografico-editrice torinese, 1913.

GOMES, Orlando, Contratos, 24a ed., Rio de Janeiro, Forense, 2001.

GOODE, Roy, The Concept of "Good Faith” in English Law, 1992, cf. disponível [online] in http://www.cisg.law.pace.edu/cisg/biblio/goode1.html.

GORDLEY, James, Impossibility and Changed and Unforeseen Circumstances, in American Journal of Compararive Law, v. 52, 2004, pp. 513-30.

, Mistake in Contract Formation, in American Journal of Compararive Law, v. 52, 2004, pp. 433-68.

GRAU, Eros Roberto, Nota sobre a Distinção entre Obrigação, Dever e Ônus, in RFDUSP, v. 77, 1982, pp. 177-83, cf. disponível [online] in http://www.revistas.usp.br/rfdusp/article/viewFile/66950/69560.

GROSHEIDE, Willem, The Duty to Deal Fairly in Commercial Contracts, in GRUNDMANN, S., MAZEAUD, D., General Clauses and Standards in European Contract Law, the Netherlands, Kulwer, 2006, pp. 197-204.

GROSS, Charles, The Court of Piepowder, in The Quarterly Journal of Economics, v. 20, n. 2, 1906, pp. 231-249, cf. disponível [online]in http://www.jstor.org/stable/1883654 [20.4.2009].

GROSSI, Paolo, L'Europa del Diritto, Roma-Bari, Laterza, 2007. , Mitologie giuridiche della modernità, trad. port. de Arnaldo Dal Ri Júnior, Mitologias jurídicas da modernidade, Florianópolis, Fundação Boiteaux, 2007. GRUNDMANN, Stefan, General Standards and Principles, Clauses Générales and Generalklausen in European Contract Law, in GRUNDMANN, S., MAZEAUD, D., General Clauses and Standards in European Contract Law, the Netherlands, Kulwer, 2006, pp. 1-19.

HACHEN, P.; SCHWENZER, I., Chaper II - General Provisions - Article 7, in SCHLECHTRIEM, P.; SCHWENZER, I. (ed.), Commentary on the UN Convention on the International Sale of Goods (CISG), 3ª ed., Oxford, New York, 2010, pp. 120-44.

HARTKAMP, Arthur S., Judicial Discretion under the New Civil Code of the Netherlands, in American Journal of Comparative Law, v. 40, 1992, p. 54, cf. disponível [online] in http://www.trans-lex.org/123700.

, Modernisation and Harmonisation of Contract Law -Objectives, Methods and Scope, in Uniform Law Review, 2003, pp. 81-96. 
, The concept of good faith in the UNIDROIT Principles, in Tulane Journal of International and Comparative Law, v. 3, 1995, pp. 65-72.

HASCHER, D., Note to ICC Award No. 5961, Clunet 1997, at 1054 et seq.

HESPANHA, António Manuel, Cultura Jurídica Européia - Síntese de um Milênio, Florianópolis, Fundação Boiteux, 2005.

O Caleidoscópio do Direito - O Direito e a Justiça nos Dias de Hoje, Coimbra, Almedina, 2007.

HESSELINK, Martijn W., The Concept of Good Faith, in HARTKAMP, Arthur, HESSELINK, Martijn W. et. al., Towards a European Towards a European Civil Code, $3^{\mathrm{a}}$ ed., Kluwer, the Netherlands, 2008, cf. disponível [online] in http://papers.ssrn.com/sol3/Delivery.cfm/SSRN_ID1098856_code88206.pdf?abstractid=1 098856\&mirid=1, pp. 619-649.

HOFFMANN, Nathalie, Interpretation Rules and Good Faith as Obstacles to the UK's Ratification of the CISG and to the Harmonization of Contract Law in Europe, v. 22, Pace International Law Review, 2010, pp. 145-18.

HUCK, Hermes, Marcelo, Sentença Estrangeira e lex mercatoria - Horizontes e fronteiras do comércio internacional, Saraiva, São Paulo, 1994.

HYLAND, Richard, Pacta Sunt Servanda - Una reflexión, in PETIT, Carlos (org.), Del Ius Mercatorum al Derecho Mercantil, Marcial Pons, Madrid, 1997, pp. 359-81.

INFANTE, F. G., Aplicação da Boa-Fé na Arbitragem Internacional, Dissertação (mestrado), USP, 2011.

JALUZOT, B., La bonne foi dans les contrats - étude comparative des droits français, allemand et japonais, Paris, Dalloz, 2001. , Methodologie du droit comparee - bilan et prospective, in Revue internationale de droit compare, 2005, v. 57, n. 1, pp. 29-48.

JARVIN, Sigvard e DERAINS, Yves, Collection of ICC Arbitral Awards 1974-1985, JARVIN, S., Note to ICC Award No.6317, Clunet 2003, at 1159 et seq.

JAUFFRET-SPINOSI, Camille, Théorie et Pratique de la Clause Générale en Droit Français et dans les Autres Systèmes Juridiques Romanistes, in GRUNDMANN, S., MAZEAUD, D., General Clauses and Standards in European Contract Law, the Netherlands, Kluwer, 2006, pp. 23-39.

JAYME, Erik, Identité culturelle et integration - Droit international privé post-moderne Cours génerale de Droit International Privé, in Recueil des cours de l'Académie de Droit International de la Haye, 1995, v. II, pp. 9-267. 
JOACHIM, Wille E., The "Reasonable Man" in United States and German Commercial Law, in Comparative Law Yearbook of International Business, 1992, v. 15, cf. disponível [online] in www.trans-lex.org/124800, pp. 341-62.

JESSUP, Philip C., Transnational Law, trad. port. deCarlos Ramires Pinheiro da Silva, Direito transnacional, Rio de Janeiro, Fundo de Cultura, 1956.

JOLIVET, E., Note to ICC Award No.10422, Clunet 2003, 1150 et seq. Note to ICC Award No. 10527, Clunet 2004, at 1268 et seq.

KAHN, Philippe, Droit international économique, droit du developpement, lex mercatoria - concept unique ou pluralisme des ordres juridiques?, in Droit des relations economiques internationales - Études offertes a Berthold Goldman, Paris, Litec, 1982, pp. 97-107.

L'interpretation des contrats internationaux, in 108 Clunet, 1981, cf. disponível [online] in www.trans-lex.org/125000, pp. 5-28. , La vente commercial internationale, Paris, Sirey, 1961. , Les principes généraux du droit devant les arbitres du commerce international, in Journal du Droit International, v. 116, n. 2, 1989, pp. 304-27.

KASSIS, Antoine, L'autonomie de l'arbitrage commercial international - le droit français en question, L'Harmattan, Paris, 2005.

, Théorie générale des usages du commerce - droit comparé, contrats et arbitrage internationaux, lex mercatoria, Libr. générale de droit et de jurisprudence, Paris, 1984.

KELSEN, Hans, Reine Rechtslehre,trad. port. de João Baptista Machado, Teoria Pura do Direito, 60 ed. São Paulo, Martins Fontes, 1999.

KERCHOVE, Michel van der; OST, François, Legal system between order and disorder, New York, Oxford, 1994.

KOMAROV, A., Mitigation of damages, in DERAINS, Y.; KREINDLER, R. H. (ed.). Evaluation of Damages in International Arbitration, Dossiers ICC Institute of World Business, 2006.

KONRADI, Wioletta; FIX-FIERRO, HÉCTOR, Lex mercatoria in the mirror of empirical research, in Sociologia del Diritto, v. 32. n. 2-3, 2005, pp. 205-27.

LAGARDE, Paul, Approche critique de la lex mercatoria, in Droit des relations economiques internationales - Études offertes a Berthold Goldman, Paris, Litec,1982, pp. $125-50$.

LALIVE, Pierre, Ordre Public Transnational (ou Réellement International) Et Arbitrage International, trad. port. de CASELLA, Paulo Borba, Ordem pública transnacional e 
arbitragem internacional - conteúdo e realidade da ordem pública transnacional na pratica arbitral, in Revista do Direito do Comércio e das Relações Internacionais, v. 1, n. 1, 1989, pp. 25-69.

LANDO, Ole, Assessing the Role of the UNIDROIT Principles in the Harmonization of Arbitration Law, in Tulane Journal of International and Comparative Law, 1994, pp. 12943. Contract law in the EU - The Commission Action Plan and the Principles of European Contract Law, disponível [online] in http://web.cbs.dk/departments/law/staff/ol/commission_on_ecl/literature/Lando/Response $\% 2016 \% 20$ May\%2003.doc [19-07-2004]. Some Features of the Law of Contract in the Third Millennium, disponível [online] in http://web.cbs.dk/departments/law/staff/ol/commission_on_ecl/literature/lando01.htm [1907-2004].

The Lex Mercatoria In International Commercial Arbitration, in International and Comparative Law Quarterly, v. 4, n. 34, 1985, pp. 747-68.

LE PAUTREMAT, S., Mitigation of Damage - A French Perspective, in x, v. 55, 2006, pp. 218.

LEÃES, Luiz Gastão Paes de Barros, Notas sobre a Boa-Fé e a Lealdade Negocial, in Il Progetto UNIDROIT "Principi per $i$ contratti commeciali internazionali" e l'unità $e$ specifità del sistema giuridico latinoamericano, BONELL, Michael Joachim e CHIPANI, Sandro (org.), Padova, Cedam, 1996, pp. 71-3.

LEVASSEUR, Alain A., Comparative Law of Contracts - Cases and Materials, Durham, Carolina Academic Press, 2008.

LOPES, José Reinaldo de Lima, As palavras e a lei-Direito, ordem e justiça na história do pensamento jurídico moderno, São Paulo, Ed. 34/Edesp, 2004. O Direito na História - Lições Introdutórias, $2^{\mathrm{a}}$ ed., São Paulo, Max

Limonad, 2002.

LOQUIN, Eric, Oú en est la lex mercatoria?, in LEBEN, Charles; LOQUIN, Eric; SALEM, Mahmoud (org.), Souveraineté étatique et marchés internationaux à la fin du 20ème siècle, à propos de 30 ans de recherche du CREDIMI - mélanges en l'honneur de Philippe Kahn, Paris, Litec, 2000, pp. 23-51.

MACINTYRE, Alasdair, After Virtue, $2^{\mathrm{a}}$ ed., Notre Dame, University of Notre Dame Press, 2003. 
MACKAAY, Ejan et. al., L'economie de la bonne foi contractuelle, in MOORE, Benoît (dir.), Mélanges Jean Pineau, Montréal, Thémis, 2003, 421-459.

MAGALHÃES, José Carlos de, "Lex Mercatoria" - Evolução e Posição Atual, in Revista dos Tribunais 709/1994, pp. 42-45.

, O Supremo Tribunal Federal e o Direito Internacional -Uma análise Crítica, $1^{\mathrm{a}}$ ed, Porto Alegre, Livraria do Advogado, 2000.

MAGGS, Gregory. E., Report concerning the United States of America, in FAUVARQUECOSSON, Bénédicte (ed.), La Confiance Légitime et l'Estoppel, Paris, Société de Législation Comparée, 2007, pp. 415-44.

MAJEED, Nudrat, Good Faith and Due Process - Lessons from the Shari'ah, in Arbitration International, 2004, v. 20, n. 1, pp. 97-112.

MALLAT, Chibli, Islamic Culture, in REIMANN, Mathias, ZIMMERMANN, Reinhard, The Oxford Handbook of Comparative Law, New York, Oxford, 2006, pp. 609-639.

MANN, Frederick A., England rejects 'delocalized' contracts and arbitration, in International and Comparative Law Quarterly, n. 33, v. 1, 1984, pp. 193-8.

MARCHI, Eduardo César Silveira Vita, Guia de Metodologia Jurídica - Teses, Monografias e Artigos, Lecce, Edizioni del Grifo, 2001.

MARRELLA, Fabrizio, La nuova lex mercatoria, Principi Unidroit ed usi dei contratti del commercio internazionale - v. XXX - Trattato di diritto commerciale e di diritto pubblico dell'economia diretto da Francesco Galgano, Padova, Cedam, 2003.

, La nuova lex mercatoria tra controversie dogmatiche e mercato delle regole - Note di analisi economica del diritto dei contratti internazionali, in Sociologia del Diritto, v. 32, n. 2-3, 2005, pp. 249-85.

MAYER, Pierre, L'avant-projet d'Acte uniforme OHADA sur les contrats - Innovations et débats, in Revue de droit des affaires internationales, n. 3, 2008, pp. 291-317.

Le Principe de Bonne Foi devant les Arbitres du Commerce International, in Festschrift Pierre Lalive, Basel, Frankfurt a.M., 1993, p. 543 e ss. , Effects of International Public Policy in International Arbitration, in

Julian D. M. Lew e Loukas A. Mistellis (ed.), Pervasive Problems in International Arbitration, The Hague, Kluwer Law International, 2006.

MAYER, Pierre, SHEPPARD, Audley, Final ILA Report on Public Policy as a Bar to Enforcement of International Arbitral Awards, in Arbitration International, v. 19, n. 2, 2003, pp. 249-63. 
MERTENS, Hans-Joachim, Lex Mercatoria - A Self-applying System Beyond National law?, in TEUBNER, Gunther (org.), Global Law Without a State, Burlington, Ashgate, 2006, pp. 31-43.

MONATERI, Pier Giuseppe, Lex mercatoria e competizione fra ordinamenti, in Sociologia del Diritto, v. 32. n. 2-3, 2005, pp. 229-40.

MORIN, A., La responsabilité fonéee sur la confiance - Étude critique des fundaments d'une innovation controverse, Genève-Bâle-München, Helbing \& Lichtenhahn, 2002.

MOSS, Giuditta Corder, International contracts between common law and civil law -is non-state law to be preferred? The difficulty of interpreting legal standards such as good faith", in Global Jurist, 7.1, 2007, cf. disponível [online] in $<$ http://find.galegroup.com/itx/infomark.do?\&contentSet=IAC-

Documents $\&$ type $=$ retrieve $\&$ tabID $=$ T002 $\&$ prodId $=$ AONE $\&$ docId $=A 163466118 \&$ source $=\mathrm{g}$ ale $\&$ srcprod=AONE\&userGroupName=capes $77 \&$ version $=1.0>$.

MUCHLINSKI, Peter T., Global Burkowina Examined - Viewing the Multinational Enterprise as a Transnational Law-Making Community, in TEUBNER, Gunther (org.), Global Law Without a State, Burlington, Ashgate, 2006, pp. 79-108.

MUSTILL, Michael, The New Lex Mercatoria - The First Twenty-five Years, in Arbitration International, 1988, pp. 86 e ss, cf. disponível [online] in www.translex.org/126900 [15.12.2009].

OLGIATI, Lex mercatoria e communitas mercatorum nell'esperienza giuridica contemporanea, in Sociologia del Diritto, v. 32, n. 2-3, 2005, pp. 351-78.

OPPETIT, B., L'Adaptation des Contrats Internationaux aux Changement de Circonstances - La Clause de Hardship aux Changement de Circonstances - La Clausede Hardship, 101 Clunet 1974, cf. disponível [online] in www.trans-lex.org/127600, pp. 794815.

Philosophie d l'arbitrage commercial international, in Journal du

Droit International, 1993, pp. 811-27.

OSMAN, Filali, Les principes généraux de la lex mercatoria - contribution à l'étude d'un ordre juridique anational, Paris, Libr. générale de droit et de jurisprudence, 1992.

OST, François, Jupiter, Hercules, Hèrmes - Trois Modelés du Juge, in BOURETZ, Pierre (org.), La Force du Droit - panorama des débats contemporains, Paris, Esprit, 1996, pp. 241-72.

PADOA-SCHIOPPA, Antonio, Brevi note storiche sulla lex mercatoria, in Sociologia del Diritto, v. 32, n. 2, 2005, pp.75-82. 
PANNARALE, Luigi, Delocalizzazione del diritto e lex mercatoria - linee-guida per una politica dei diritti in una società transnazionale, in Sociologia del Diritto, v. 32, n. 2-3, 2005, pp. 309-28.

PAULSSON, J., Arbitration in Three Dimensions, LSE Law, Society and Economy Working Papers 2/2010, cf. disponível [online] in www.lse.ac.uk/collections/law/wps/wps.htm. El orden público como criterio para negar el reconocimiento y la ejecución de laudos arbitrales, in TAWIL, G. S., ZULETA (ed.), El Arbitraje Comercial Internacional Estudio de la Convención de Nueva York con Motivo de su 50 Aniversario, Buenos Aires, Abeledo Perrot, 2008, pp. 609-16.

, La Lex Mercatoria dans l'Arbitrage C.C.I., in Revue de l'Arbitrage, 1999, cf. disponível [online] in www.trans-lex.org/127800, pp. 55-103.

PICCIOTO, Sol, Regulatory Networks and Global Governance, cf. disponível [online] in http://eprints.lancs.ac.uk/232/1/reg_networks_\&_glob_gov.pdf [3.1.2010]

PELLET, Alain, La lex mercatoria "tiers ordre juridique"? - remarques ingenues d'un internationaliste de droit publique, in LEBEN, Charles; LOQUIN, Eric; SALEM, Mahmoud (org.), Souveraineté étatique et marchés internationaux à la fin du 20ème siècle, à propos de 30 ans de recherche du CREDIMI - mélanges en l'honneur de Philippe Kahn, Paris, Litec, 2000, pp. 54-74.

PINSOLLE, P., Distinction entre le principe de l'estoppel er le principe de bonne foi dans le droit du commerce international, in Journal du Droit International, 1998, pp. 905-931.

PUREZA, José Manuel, Defensive and oppositional counter-hegemonic uses of international law - from the international criminal court to the common heritage of humankind, in SANTOS, Boaventura de Sousa; RODRIGUEZ-GRAVITO, César A. (ed.), Law and Globalization from Below - Towards a Cosmopolitan Legality, Cambridge, 2005, pp. 267-80.

QUEIROZ, Everardo Nóbrega de, O Princípio da Boa-fé Objetiva ou da Razoabilidade como fundamento Jurídico da Lex Mercatoria, in AMARAL JÚNIOR, Alberto do (coord), Direito do Comércio Internacional, Juarez de Oliveira, São Paulo, 2002, pp. 79-104.

RÁO, Vicente, O Direito e a Vida dos Direitos, 6a ed., São Paulo, RT, 2004.

REALE, Miguel, Lições Preliminares de Direito, $7^{\mathrm{a}}$ ed., São Paulo, Saraiva, 1980.

RECHSTEINER, Beat Walter, Direito Internacional Privado - Teoria e Prática, $8^{\mathrm{a}}$ ed., São Paulo, Saraiva, 2005. 
REIFEGERSTE, Stephan, WEISZBERG, Guillaume, Obligation de minimiser le dommage et 'raisonnable' en droit du commerce international in Revue du Droit des Affaires Internationaux, n. 2, 2004, pp. 181-97.

RENSMANN, Thilo, Anational arbitral awards - legal phenomenon of academic phantom?, in Journal of International Arbitration, v. 15, n. 2, 1998, pp. 37-65.

ROBIN, Guy, Le principe de la bonne foi dans les contrats internationaux, in Revue de droit des affaires internationales, 2005, n. 6, pp. 695-727.

, Les dommages et intérêts punitifs dans les contrats internationaux, in Revue de droit des affaires internationales, 2004, n. 3, pp. 247-67.

ROMAIN, Jean-François, Théorie critique du principe general de la bonne foi en droit privé, Bruxelles, Bruylant, 2000.

ROMANO, Santi, L'ordinamento giuridico, trad. franc. de Lucien François e Pierre Gothot, L'ordre juridique, 2a ed., Paris, Dalloz, 2002.

ROMERO, Eduardo S., Note to ICC Award No. 10671, Clunet, 2006, pp. 1423-, cf. disponível [online] in www.trans-lex.org/196106.

, Note to ICC Award No. 11426, in Clunet, 2006, pp. 1450-4, cf. disponível [online] in www.trans-lex.org/196114.

RONGEAT-OUDIN, Federica, OUDIN, Martin, La reception des Principes UNIDROIT par la lex mercatoria - l'exemple de la bonne foi, in IBLJ, n. 6, 2009, pp. 697-722.

ROSETT, Arthur, The many paths to harmony in international commercial law, in New rends in International Trade Law - Contributions on the Occasion of the 10th Anniversary of the International Trade Law Course, Torino, G. Giappicheli, 2000, pp. 319-24. , Unification, Harmonization, Restatement, Codification and Reform in International Commercial Law, in The American Journal of Comparative Law,1992, pp. 688-97.

ROULAND, Norbert, Aux confins du droit, trad. port. de Maria Ermantina de Almeida Prado Galvão, Nos Confins do Direito, $1^{\text {a }}$ ed., São Paulo, Martins Fontes, 2003.

SACCO, Rodolfo, Antropologia giuridica - contributo ad una macrostoria del diritto, Bologna, Il Mulino, 2007.

SACCO, Diversity and Uniformity in the Law, in The American Journal of Comparative Law, 2001, v. 49, pp. 171-90.

SACHS, Stephen E., From St. Ives to cyberspace - the modern distortion of the medieval law merchant, in American University International Law Review, v. 21, n. 5, 2006, pp. 685-812. 
SANTOS, Boaventura de Sousa (org.), Conhecimento Prudente para uma Vida Decente Um Discurso sobre as Ciências Revisitado, São Paulo, Cortez, 2004.

SANTOS, Boaventura de Sousa, Notas sobre a História Jurídico-Social de Pasárgada, pp. 107-17, in SOUTO, Cláudio; FALCÃO, Joaquim (org.), Sociologia Jurídica - leituras básicas de sociologia jurídica, São Paulo, Pioneira, 1980.

SANTOS, Boaventura de Sousa, law - A Map of Misreading - Toward a Post-Modern Concept of Law, in Journal of Law and Society, v. 14, n. 13, 1987, pp. 279-302.

SANTOS, Boaventura de Sousa; RODRIGUEZ-GRAVITO, César A., Law, politics, and the subaltern in counter-hegemonic globalization, in SANTOS, Boaventura de Sousa; RODRIGUEZ-GRAVITO, César A. (ed.), Law and Globalization from Below - Towards a Cosmopolitan Legality, Cambridge, 2005, pp. 1-26.

SCHLECHTRIEM, P., Uniform Sales Law - The UN-Convention on Contracts for the International Sale of Goods, Manz, Vienna, 1986 (excerto disponível [online] em http://www.cisg.law.pace.edu/cisg/biblio/schlechtriem-07.html)

SCHMITTHOFF, Clive, International Business law - A New Law Merchant, in Select Essays on International Trade, Chia-Jui Cheng (ed.), Dortrecht, Boston, London, Martinus Nijhoff Publishers e Graham\&Trotman, 1988, pp. 20-37.

Nature and Evolution of the Transnational Law of Commercial Transactions, in Selected Essays on International Trade Law, Dortrecht, Boston, London, Martinus Nijhoff Publishers e Graham\&Trotman, 1988, pp. 231-42.

SCHULZ, Alexandre Buono, A ordem pública na Convenção de Nova Iorque sobre Reconhecimento e a Execução de Sentenças Arbitrais Estrangeiras, in RBA, n. 38, 2013, pp. 65-95.

Os contratos comerciais internacionais na sociedade pós-industrial - reflexões sobre a nova lex mercatoria, Dissertação (mestrado), USP, 2010.

SENADO FEDERAL, Novo Código Civil - Exposição de Motivos e Texto Sancionado, Senado Federal, Brasília, 2002, p. 342, p. 43-44.

SHAH, Prakash, Legal Pluralism in Conflict - Coping with Cultural Diversity in Law, Cooggee, Cavendish Publishing, 2005.

SHMATENKO, Leonid, Is Lex Mercatoria Jeopardizing the Application of Substantive Law?, in Czech (\& Central European) Yearbook of Arbitration, v. 13, 2013, pp. 89-108.

SIMS, Vanessa, Good faith in contract law - of triggers and concentric circles, in The King's College Law Journal, n. 16, 2005, pp. 293-310. 
SNYDER, Francis, Economic Globalisation and the Law in the $21^{\text {st }}$ Century, cf. disponível [online]

snyder.com/tl_files/contents/articles/Economic_Globalisation_and_the_Law_in_the_21st_ Century_fin.pdf [3.1.2010].

SPENCE, J. R., Legitimate Expectations and Unlawful Representations, in Cambridge Law Journal, v. 63-2, 2004, 261-316.

STRENGER, Irineu, Contratos Internacionais do Comércio, $3^{\text {a }}$ ed., São Paulo, LTr, 1998. , Da Autonomia da Vontade - direito interno e internacional, $2^{\mathrm{a}}$ ed., São Paulo, LTr, 2000.

Direito do Comércio Internacional e Lex Mercatoria, São Paulo, LTr, 1996.

SUCHANKOVA, Martina, The Unidroit Principles of International Commercial Contracts and the Precontractual liability in the Event of Failed Negotiations, in Revue de droit des affaires internationales, n. 6, 1997, pp. 691-702.

SUMMERS, Robert S., The conceptualistaion of good faith in American contract law - a general account, in ZIMMMERMANN, Reinhard, WHITTAKER, Simon (ed.), Good Faith in European Contract Law, Cambridge, Cambridge, 2000, pp. 118-41.

SUPIOT, Alain, Homo Juridicus - Essai sur la function anthropologique du droit, trad. port. de Maria Ermantina de Almeida Prado Galvão, Homo Juridicus - ensaio sobre a função antropológica do direito, São Paulo, Martins Fontes, 2007.

TERRÉ, Dominique, Le pluralisme et le droit, in Archives de philosophie du droit, n. 49, 2006, pp. 69-83.

TETLEY, William, Good Faith in Contract - Particularly in the Contracts of Arbitration and Chartering, in Journal of Maritime and Commercial Law, n. 35, 2004, cf. disponível [online] in http://www.mcgill.ca/files/maritimelaw/goodfaith.pdf, pp. 561-616.

TEUBNER, Gunther, 'Global Burkowina' - Legal Pluralismin the World Society,in TEUBNER, Gunther (org.), Global Law Without a State, Burlington, Ashgate, 2006, pp. 3 28.

Breaking Frames-La globalizzazione economica e l'emegere della lex mercatoria, in La cultura del diritto nell'epoca della globalizzazione - L'emergere delle costituzioni civili, Roma, Armando, 2005.

, Direito, Sistema e Policontexturalidade, Piracicaba, UNESP, 2005.

TREVES, Tullio, Lex Mercatoria Dei Naviganti, in Sociologia del Diritto, v. 32, n. 2-3, 2005, pp. 379-82. 
TWINING, William, Globalization and legal theory, New York, Cambridge, 2006.

VAN DEN BERG, Albert Jan, The New York Arbitration Convention of 1958: Towards a Uniform Judicial Interpretation, The Hague, Kluwer Law International, 1981.

VAN ERP, Sjef, Good faith - a concept unworkable in practice - A case note on Walford v. Miles, in Tilburg Foreign Law Review, v. 1, 1991-1992, pp. 215-22.

VAN HOUTTE, H., Changed Circumstances and Pacta Sunt Servanda in GAILLARD, Emmanuel (ed.), Transnational Rules in International Commercial Arbitration, Paris, ICC Publishing, n. 480, 1993, cf. disponível [online] in www.Trans-Lex.org/117300, pp. 10525 .

VANDERLINDEN, Jacques, Le pluralisme juridique - essai de synthèse, in GILISSEN, John (org.), Le pluralisme juridique, Bruxelles, Université de Bruxelles, 1971, pp. 19-56.

VIRALLY, Michel, Un tiers droit? - refléxions theoriques, in Droit des relations economiques internationales - Études offertes a Berthold Goldman, Paris, Litec,1982, pp. 373-85.

VOLCKART, Oliver, Are the Roots of the Modern Lex Mercatoria Really Medieval?, in Southern Economic Journal, v. 65, n. 3, 1999, pp. 427-450, cf. disponível [online] in http://www.jstor.org/stable/1060808 [20.4.2009]

VON BAR, Christian, CLIVE, Eric, SCHULTE-NÖLKE, Hans, Principles, Definitions and Model Rules of European Private Law - Draft Common Frame of Reference (DCFR) Prepared by the Study Group on a European Civil Code and the Research Group on EC Private Law (Acquis Group), Munique, Sellier, 2009, cf. disponível [online] in http://ec.europa.eu/justice/contract/files/european-private-law_en.pdf.

WALLERSTEIN, Immanuel, European Universalism - The Retoric Of Power, trad. port. de Beatriz Medina, O Universalismo Europeu - A Retórica do Poder, São Paulo, Boitempo, 2007.

WEISZBERG, Guillaume, Le "Raisonnable” en Droit du Commerce International, Tese (doutorado), Université Panthéon-Assas (Paris II), 2003, cf. disponível [online] in http://cisgw3.law.pace.edu/cisg/biblio/Reasonableness.html.

WHITE\&CASE, 2010 International Arbitration Survey: Choices in International Arbitration, cf. disponível [online] in http://choices.whitecase.com/.

WIEACKER, Franz, Privatsrechtgeschichte der Neuzeit unter Besonderer Berücksichtigung der Deutschen Entwicklung, trad. port. de António Manuel Botelho Hespanha, História do Direito Privado Moderno, 2a ed., Lisboa, Calouste Gulbenkian, 1967. 
YEE, Woo Pei, Protecting Parties' Reasonable Expectations - A General Principle of Good Faith, in Oxford University Commonwealth Journal, v. 1, n. 2, 2001, pp. 195-229.

ZELLER, B., Good faith - Is it a contractual obligation?, in Bond Law Review, v. 15, n. 2 , 2003, disponível [online] in http://epublications.bond.edu.au/blr/voll5/iss2/13, pp. 215-39. , Good Faith - The Scarlet Pimpernel of the CISG, cf. disponível [online] in http://www.cisg.law.pace.edu/cisg/biblio/zeller2.html.

ZIMMMERMANN, Reinhard, WHITTAKER, Simon, Coming to terms with good faith, in ZIMMMERMANN, Reinhard, WHITTAKER, Simon (ed.), Good Faith in European Contract Law, Cambridge, Cambridge, 2000, pp. 653-701.

, Good faith in European Contract Law - Surveying the Legal Landscape, in ZIMMMERMANN, Reinhard, WHITTAKER, Simon (ed.), Good Faith in European Contract Law, Cambridge, Cambridge, 2000, pp. 7-62.

ZUPPI, A. L., The Parol Evidence Rule - A Comparative Study of the Common Law, the Civil Law Tradition, and Lex Mercatoria, in Georgia Journal of Comparative and International Law, v. 35, n. 2, 2007, pp. 235-76. 